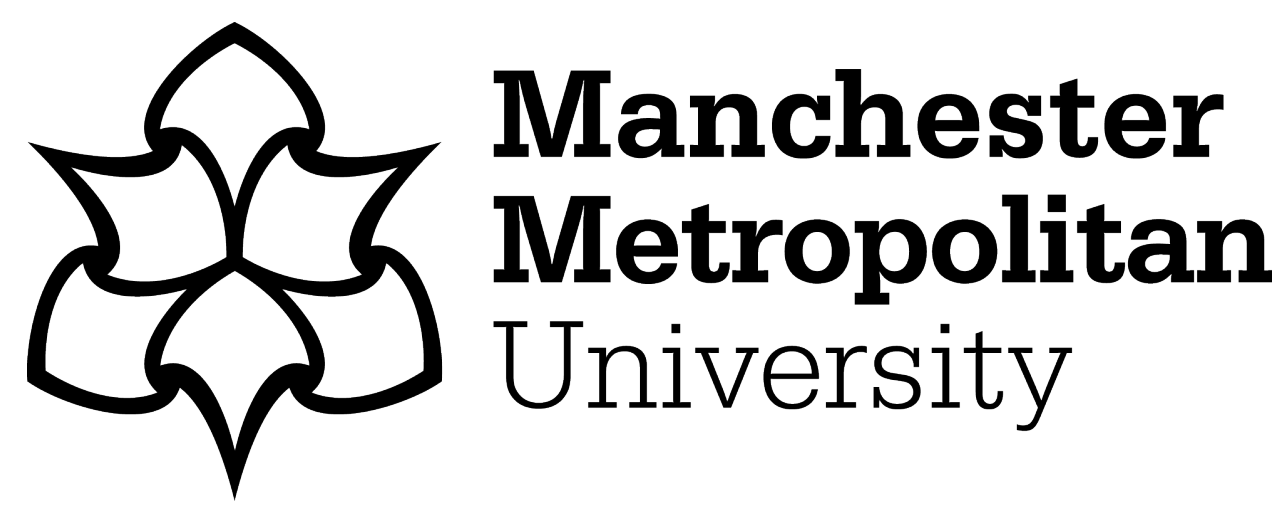

Gibson, Luke and Groom, Ryan (2020) Developing a professional leadership identity during organisational change in professional youth football. Qualitative Research in Sport, Exercise and Health, 12 (5). pp. 764-780. ISSN 2159-676X

Downloaded from: https://e-space.mmu.ac.uk/624126/

Version: Accepted Version

Publisher: Informa UK Limited

DOI: https://doi.org/10.1080/2159676x.2019.1673469

Please cite the published version 


\section{Developing a professional leadership identity during organisational change in professional youth football}

Accepted for publication 24/09/19

Qualitative Research in Sport, Exercise and Health

${ }^{1}$ Luke Gibson* and ${ }^{2}$ Ryan Groom

${ }^{1}$ University of Derby, Sport, Outdoor and Exercise Science, Derby, UK.

ORCID: http://orcid.org/0000-0002-8401-8480

${ }^{2}$ Manchester Metropolitan University, Department of Sport and Exercise Science,

Manchester, UK. ORCID: http://orcid.org/0000-0001-7633-3846

* Corresponding author: Luke Gibson, Sport, Outdoor and Exercise Science, Department of Life Sciences, College of Life and Natural Sciences, University of Derby, Derby, DE22 1GB 1.gibson@derby.ac.uk

\section{To Cite:}

Gibson, L., \& Groom, R. (2019). Developing a professional leadership identity during organisational change in professional youth football. Qualitative Research in Sport Exercise \& Health. DOI: 10.1080/2159676X.2019.1673469 


\title{
Developing a professional leadership identity during organisational change in professional youth football
}

\begin{abstract}
The purpose of this paper is to investigate the construction of a professional leadership identity of an outsider appointed to implement organisational change within the academy of a professional football club. Data were collected through field notes, informal observations and meetings, formal academy team meetings, three in-depth co-worker interviews and four semi-structured in-depth participant interviews, which were subjected to an iterative analysis. Findings highlighted how the appraisal of others and their appraisal of the participant were affected by employment vulnerability, and that 'identity work' when leading organisational change was intertwined with micro-political literacy and micro-political action. This study furthers understanding of the development of a leadership identity as a fluid and fragmented struggle, by demonstrating that the process of identity construction is emotional work and is entwined in a complex interplay of micro-political literacy and action, and employment vulnerability.
\end{abstract}

Keywords: Organisational change, Professional football, Micro-politics, Professional identity, Narrative analysis 


\section{Introduction}

Organisational change is an increasingly evident feature of the competitive and dynamic nature of organisational life (Petrou, Demerouti and Schaufeli, 2018). Therefore, understanding the process of organisational change is central to organisational studies (Armenakis and Bedeian, 1999; Pettigrew, Woodman and Cameron, 2001; Van de Ven and Poole, 2005). Typically, research that examines organisational change follows an analysis of observed differences in variables over time (i.e. variance theory) or an event-driven (i.e. process theory) narrative approach (Van de Ven and Poole, 2005). Variance theory methodologies entail the statistical analysis of quantitative data, where change is analysed as the impact of a set of independent variables upon the dependent variable of change (Van de Ven and Poole, 2005). When organisational change is examined from a process theory or narrative perspective, the change process is illuminated through the temporal order and sequence in which the change events occurred, based upon social actors re-telling the narrative events (Van de Ven and Poole, 2005). Importantly, process theory methodologies are particularly useful for understanding the sensemaking process of individuals, when change is conceptualized as context-dependent, unpredictable, and non-linear, and where intended strategies often lead to unintended consequences (Balogun and Johnson, 2005; Heyden, Fourné, Koene, Werkman, and Ansari, 2017).

During the process of organisational change, the appointment of the change agent in the organisation, as an insider to the organisation (i.e. those managers who have been promoted internally) or as an outsider (i.e. those managers who have been appointed externally), can have a significant impact on the nature of the change. For example, outsiders to the organisation differ from insiders, as their vision for change can be less constrained by the organisation's internal resources and organisational history (Zhang and Rajagopalan, 2010). This is because internal managers often have a deeper understanding of the way that the organisation operates 
and are therefore more likely to build change upon existing capabilities in an incremental manner (Zhang and Rajagopalan, 2010). In addition, research that has examined organisational change has typically taken a 'top-down' management perspective, examining the role of a CEO or top manager in implementing change, which is then reluctantly executed by middle managers, whilst the 'bottom-up' perspective focuses upon the importance of the middle managers in initiating change (Heyden et al., 2017). However, there is a paucity of work which examines middle managers' sensemaking, particularly when middle managers have been appointed externally to the organisation (Balogun and Johnson, 2005; Heyden et al., 2017; Zhang and Rajagopalan, 2010).

During the change process the strategic and political formation of managerial identities is intertwined with organisational discourse and practice (Alvesson and Sveningsson, 2003a, 2003b; Alvesson and Willmott, 2002; Sveningsson and Alvesson, 2003). For example, Alvesson and Willmott (2002) highlighted that through a process of self-positioning and identity regulation, employees develop self-images and work orientations that align to managerial objects. Similarly, Sveningsson and Alvesson (2003b) have demonstrated some of the conflicting organisational discourses and tensions that managers dealt with when seeking to enact 'good' leadership and management practices in an attempt to display a proactive, visionary, and strategic identity without appearing to display the potentially negative image of engaging in bureaucratic micro-management and organisational control-oriented activities. Such organisational micro-political activity can be understood as "an attempt to exert a formative influence on social structures and human relations" (Dörrenbächer and Geppert, 2006, p. 256). Kelchtermans and Ballet (2002) define micro-politics as "strategies and tactics used by individuals and groups in organisations to further their interests" (p. 107). Therefore, organisational micro-political activity is contested, and conflicts are an everyday occurrence when attempting to realize interests (Dörrenbächer and Geppert, 2006). Whilst only a few 
powerful key actors usually engage in micro-political strategizing, the effects of "their interactions can have far reaching consequences for all members of the organisation" (Dörrenbächer and Geppert, 2006, p. 256). Zhang and Rajagopalan (2010) have called for future studies to draw upon qualitative methodologies to contribute to a deeper understanding of the dynamics and strategies used to implement strategic change. Similarly, Koveshnikov, Vaara and Ehrnrooth (2016) have highlighted that within the field of organisational studies there is a "paucity of knowledge regarding micro-political activities", in particular, the process of managers and leaders engaging in micro-political "identity construction or identity work" during the change process (p. 1353).

Following a narrative process theory approach, the aim of this study is to examine the sensemaking process of a middle manager who had been appointed externally to the organisation, with a remit to implement and support organisational change. The specific focus of this paper is to further understand the role of micro-political activity in managerial identity construction work during the process of organisational change. In their examination of organisational change within professional football, Wagstaff, Gilmore and Thelwell (2016) highlighted that there is a need for further research within sporting organisations from an embedded ethnographic perspective, to provide a rich temporal and emotional understanding of organisational change. The research site for this study, Smithstown FC (pseudonym), is a professional English Football League club. Professional sport offers a highly competitive and dynamic environment in which to study organisational life (Brown and Coupland, 2015; Wagstaff et al., 2016). Characterised by high levels of cultural and organisational change, insecure work, and employment vulnerability, professional football in particular is an important part of the social fabric of society and an under-researched organisational context (Gilmore and Gilson, 2007; Ogbonna and Harris, 2015; Roderick, 2006; Wagstaff et al., 2016). 
Four interrelated research questions guide this study to explore the participant's experiences of the change process in professional football:

1. How and why was the participant appointed to the organisation during the process of organisational change?

2. What were the participant's remit and responsibilities within the organisation during the change process?

3. How did the participant interact with others during the change process as part of this remit?

4. In what sense did the participant coach come to understand the micro-political realities of organisational change?

In attempting to address these questions, this study seeks to further our understanding of the political and highly competitive nature of professional youth sport and the role of an outsider recruited to initiate and support organisational change. This work aims to illuminate how an outsider to the organisation developed his own managerial identity through micropolitical action. This work also seeks to further our understanding of organisational micropolitical activity and professional identity negotiation during the change process (Alvesson and Sveningsson, 2003a, 2003b; Alvesson and Willmott, 2002; Sveningsson and Alvesson, 2003).

\section{Methodology}

\section{Philosophical underpinnings}

An interpretive, nested case study research design was rigorously developed, informed by an ideographic research methodology (Berger and Luckmann, 1996; Polkinghorne, 2007; Thomas, 2016). The research project was underpinned by a relativist ontology that recognised that there is no reality independent of perception, and reality is multiple, created, and mind- 
dependent (Berger and Luckmann, 1996; Polkinghorne, 2007; Smith, 2013). Epistemologically, our approach was informed by constructionism, in that knowledge is constructed through social interactions and the social world is subjective in nature (Berger and Luckmann, 1996; Polkinghorne, 2007; Smith, 2013; Sparkes and Smith, 2008).

Thacher (2006) outlines that the interpretive case study focuses on illuminating the subjective meaning attached to human action, and that "interpretive case studies offer explanations, since identifying the world or motives that lead people to behave in a particular way is also arguably a way of explaining their behaviour" (Thacher, 2006, p. 1635). Furthermore, Ruddin (2006) highlights the notion of naturalistic generalisation associated with the interpretive approach, as opposed to generalisability, by suggesting "a move away from external validity, towards the provision of sufficient contextual information to facilitate the reader's judgement as to whether a particular case can be generalised to a specific field of practice" (p. 804).

\section{Research design and context}

The present case study forms part of a larger multiple participant nested project at a professional football club called Smithstown FC (pseudonym), with academy staff Dave, Jack, Michael, and Danny (pseudonyms) (see Table 1). At the time of data collection, Smithstown FC was a professional football league club. In this particular study, the findings and rich empirical insights from Jack (pseudonym) are presented. Following an iterative reading of the data and micro-political theorising, this study focused upon Jack's interpretations of the situation he found himself in and the behaviours of staff within the club during the process of organisational change. 


\section{The participant}

Institutional ethical approval was granted by the University Ethics Committee prior to data collection taking place. The study was initiated following the appointment of a new Chairman, Board of Directors and $1^{\text {st }}$ Team Manager, who all indicated that Smithstown FC would be undergoing a period of organisational change. The participant, Jack, was approached a year after his appointment and he agreed to take part in the study and provided informed consent. At the time of the data collection, Jack was Head of Professional Development Phase at Smithstown FC. Jack's coaching qualifications include the UEFA (Union of European Football Associations) Advanced Licence (UEFA A) and the English FA (Football Association) Youth Award.

Jack was appointed as the Head of Professional Development Phase two months after the appointment of a new 1st Team Manager, and nine months after the arrival of a new Chairman and Board of Directors. His primary responsibility as the Head of Professional Development Phase was for players and staff within the Professional Development Phase of the academy (U18-U21 age groups). Within this phase, Jack managed a group of staff that consisted of a full-time Physiotherapist, a full-time Sport Scientist, a full-time Video Analyst and 22 full-time players. In addition, Jack also assisted the Academy Manager (Dave) in overseeing the day-to-day running of the academy. Indeed, Jack was appointed to the role of Head of Professional Development Phase to implement change within his phase (U18-U21 age groups), but also to support the Academy Manager in implementing changes throughout the rest of the academy age groups (U8-U16 age groups).

\section{Data collection}

Data were collected by the principal author, and consisted of ethnographic field notes and observations from informal meetings, formal academy staff team meetings, in-depth interviews 
with three co-workers regarding the period of organisational change (i.e. Dave, Michael, and Danny; see Table 1), and four in-depth, semi-structured interpretive interviews with Jack. However, prior to the commencement of the semi-structured interview process, the primary researcher had left his role as academy coach and was solely a researcher. The interviews focused on Jack's experiences of being appointed as an outsider into an academy department within a professional football club during a period of organisational change. Moreover, the interviews were informed by previously collected ethnographic field notes, observations from informal meetings, formal academy staff team meetings and co-worker interviews. Specifically, Jack was prompted to describe his experiences of discussing his remit with the Chairman and 1st Team Manager following his appointment, his working relationships with new colleagues, and the challenges to his sense of self and identity as a coach within his new role.

Prior to the start of the first interview, Jack was made aware of the nature of the data collection process, the aim of the research project, how the research would be disseminated, and issues surrounding the confidentiality of peers or colleagues discussed within the data. Jack was also made aware of his right to withdraw at any point during the study and to withdraw permission to publish the final analysis of his narrative. The interpretive interviews were conducted with Jack in a quiet and private setting at his convenience. The interviews with Jack resulted in around five hours of audio-recorded conversation in total.

\section{Narrative data analysis}

Each interview with Jack was audio-recorded, transcribed verbatim, and analysed through a process of iterative analysis to inform subsequent interviews. Specifically, the research team focused on data that provided an insight into Jack's experiences of developing new working relationships with staff as an outsider coming into the club and implementing change. As part 
of the iterative process, the data were subjected to a process of inductive analysis to support the exploration of Jack's experiences in relation to the phenomena under investigation. Specifically, the narrative analysis focused on how the participant interacted in the settings with key characters during a plotline of critical incidents in his employment at a professional football club during a period of organisational change (Smith, 2013; Smith and Sparkes, 2005; Smith and Sparkes, 2008). This analysis was conducted through the lens of previous literature that has investigated micro-political identity (Alvesson and Willmott, 2002; Croft, Currie and Lockett, 2015; Kelchtermans, 2009; Kelchtermans and Ballet, 2002). Following completion of the first interview, analytical memos were used to determine links to the theory within the data, to 'make sense' of Jack's experiences. Whilst the use of an interpretive approach to investigating micro-politics and identity has been supported by previous work (e.g. Wright, Nyberg and Grant, 2012), the representation or re-representation of Jack's experiences should be considered. Specifically, the following interpretations and final representation have developed through the process of co-construction with Jack and the research team (Berger and Luckmann, 1996; Polkinghorne, 2007; Smith, 2013).

\section{Results and Discussion}

\section{Getting the job and role expectations}

Following changes at the club, a new Chairman, Board of Directors and 1st Team Manager reviewed the performance of the academy and relieved the then Head of Professional Development Phase (Ally, pseudonym) of his duties before appointing Jack as a replacement in this role. Jack explained how the initial contact that lead to his appointment occurred:

The Gaffer rang me up when I was at Bolder (pseudonym) ... 'would you like to come back into full-time football?' I thought twice about it because I'd been 
out of work for a bit. I knew the Gaffer pretty well ... I met with the Chairman who told me about the vision.

With the club undergoing such significant change, Jack sought assurances from the 1 st Team Manager: 'I don't want to take this job knowing in six months' time a new manager comes in and you're surplus to requirements.' Jack reported that the conversation continued with an explanation from the 1st Team Manager:

'That won't happen.' he says. You can't have that written in your contract that you're never going to get sacked. But you have to take people on face value. I met the Chairman; his first words were 'We're bringing you in because we've not had a product in the first team for nearly seven years. Smithstown Football Club is just not producing. We'd like you probably to get involved with some reserve games as well, but your remit is to improve the youth side of things. That's your job and your remit.'

A similar rationale for employing staff from outside of existing organisations is reflected in previous literature, with outsiders recruited to bring new knowledge and skills into the organisation (Zhang and Rajagopalan, 2010). Previous work has demonstrated the important role of the 1st Team Manager and the Academy Manager in the development of academy players for the 1st Team (Author and Author, 2018a; Gilmore and Gilson, 2007). Whilst the work of Author and Author (2018a) highlights the importance of a vision for change in academy settings, Gilmore and Gilson (2007) further highlight the importance of the longterm contractual security of the 1st Team Manager in supporting the development of a club's academy. 
After meeting both the 1st Team Manager and Chairman, Jack reflected upon the offer: 'That's when you've got to make sure everything is right for yourself. I felt confident. You know, I thought "I've done it before, I've worked with pros [senior professional players] at Westfield [pseudonym], this should be a piece of cake." However, Jack was also aware that his appointment meant that someone else (Ally) lost their job:

Obviously, somebody lost their job because I was coming in which I knew about and was a bit awkward. You have to deal with that. But you also have to get to work and analyse how you can make a difference within the first two or three weeks. What needs doing? How can I affect this? Prioritise really.

Similar findings have been illustrated by Wagstaff et al. (2016) in their examination of organisational change in professional football. Specifically, participants from the study completed by Wagstaff et al. (2016) explained that managerial and organisational change is the nature of the sports industry and over time employees become accustomed to dealing with change.

\section{Addressing the remit and developing the business}

Whilst initially the Chairman had described Jack's remit as being to develop players for the 1st Team, it soon became apparent that developing players to sell for a financial return was the primary purpose of Jack's remit:

The Chairman said to me 'I need to make it a business, Jack'. He's putting in money on top of the Football League funding we're getting. He's a successful businessman so he'll come at it from a business sense too. We've got a 
department that's going to have to pay for itself. So, with that, I'm going to have to make lads attractable to a certain clientele. Who is going to potentially buy these lads? Top Premier League clubs? Top Championship clubs? Who's got the most money? Premier League clubs. I'm going to have to make them [players] desirable. What are they looking for? Technically strong, athletic thinkers.

Jack's awareness of the need to make the academy a business prompted reorganisation of his managerial identity to achieve his remit of developing players who could become saleable assets to a specific market. Alvesson and Willmott (2002) found that employees create self-images and work orientations that are consistent with the objectives they are tasked with by superior leaders within organisations. Jack continued to discuss questions he posed to both himself and his staff: 'How do we change the perception within the club? How do we go from "Well, we've only got two lads who got pro contracts this year, so that's a success as a youth [department], we finished sixth in the league ... we're s**t but that's us, we can't do anymore, we're a s**t club, we haven't got any scouts ..." How do we go from that to getting a title winning team within six to twelve months of coming in? How do we get lads appearing in the first team? How's it done? It's changing a mind-set, it's having a focus and a vision of what you want, it's implementing it.'

During periods of organisational change in professional football, the work of Gilmore and Gilson (2007) has demonstrated the importance of a philosophy driven by innovation when competing against other clubs with limited resources, whilst Author and Author (2018a, 2018b) have illustrated the importance of staff that are willing to buy into a vision of change or be 'moved on'. Jack continued to discuss an overview of the strategy that was implemented to help generate business and attract interest from the 'top Premier League' and 'top 
Championship' football clubs: 'The most lucrative market is Under 23 level. I have to attract the scouts initially, get the interest. If I can get that interest bubbling because they're technically strong, they're athletic - interest. Then we play in them in our first team, boost the profile even more.' By generating that initial interest from the scouts and then raising the profile of the player by playing him in the 1 st Team, Jack highlighted the financial returns that his department had made since implementing this strategy, underlining the relative success he had achieved:

We’ve done close to $£ 1.4$ million just in down payments in just over 12 months. For a [English Football] League One club that's never had a player anywhere near ... we've had 13 [1st Team] debuts, with an Under 16 that is currently playing in centre midfield that could probably be worth well over a million pound. There's probably three to four million worth of talent stockpiled at Under 16s.

Jack further elaborated on his assessment of the Under 16 age category and outlined the review process for players in each age group within the academy:

You have three grades you might have 'saleable' - say they're in the Under 14s or Under $15 \mathrm{~s}$ and there's interest [from Premier League or Championship clubs]. You might have 'potential for scholarship' [two-year contract given to players at Under 16 to continue training full time until Under 18] and you might have 'release' or 'bottom end' if you're not expecting much. 
Jack highlighted that the recruitment process meant that 'all kids now have to have a selling point; they have to be outstanding at something then we can work with the rest'. Whilst relative success had been achieved in terms of his remit since his arrival, Jack was aware of the potential questions that may be asked if the production of players and the business did not keep up the same pace. He discussed this situation: 'What I find at the moment is people are coming in now and they think this is normal. It's not normal, it's not. Getting one [player] in your 1st Team every three or four years is normal.' Further discussions prompted Jack to outline his thoughts on questions around this issue:

There will be a time when it dries up and then what's the perception of people towards us? 'What's going on? Where's the next one [player]?' ... 'Well, we've made you all this?' ... 'No, but where's the next one? Why haven't we got another one?' ... 'Well, they don't grow on trees'. That would come. We are careful as a coaching staff. It's very easy at the moment to get pats on the back and take all the glory. We just have to say, 'Right, next year we might not be productive.' You know, we've got an age group coming up soon and there's not much in there. So, we have to plan.

The work of Kelchtermans (2009) illuminated similar sources of employment vulnerability for teachers as are reported within the present study. Kelchtermans (2009) highlights that employment vulnerability encompasses both emotions (feelings) and cognitive processes (perception, interpretation). Specifically, Jack highlighted concerns about the possibility of a negative perception of him and his staff if they did not continue to perform against the measurement of producing players who were saleable assets. Within the teaching profession, Kelchtermans (2009) found that negative student performance in test scores led to 
teachers sensing a negative perception of their identity as a good teacher and therefore to feeling vulnerable within the working environment. To understand Jack's assertion that players 'don't grow on trees', there are factors that influence the successfulness of his role that are out of his control, such as player recruitment and other issues that contribute to player development. Kelchtermans (2009) explained that such employment vulnerability stems from a lack of control of organisational working conditions.

\section{Staff character appraisals}

In order to successfully address the remit given to him and develop the business, Jack was required to consider the current staff in his department and to determine which staff would best support him in fulfilling the remit. Jack recalled:

You've got a Sport Scientist that's been employed by the previous guy, he's working with you every day. He's in the office with you every day. I've got a Physio I've never met in my life, I've never met Michael, I've never met Dave. They're our youth full-time set up. I've come in now and everybody is looking at me to say, 'Right, what are we doing?'

Jack's experience as a new leader coming into an already existing department was that it brought about an increased level of expectation and he had the perception of 'being judged' by his new staff. Similarly, the work of Denis, Langley and Cazale (1996) found that moving into leadership roles brings about increased visibility and multiple pressures. Within the context of professional football, Roderick (2006) highlighted the "heightened selfconsciousness associated with increased levels of visibility inside a football club" (p. 259). 
When considering this initial period, Jack provided an insight into the political behaviour he employed during the appraisal process of the Sport Scientist (Derek):

He was a bit weird, Derek, a bit strange. This is the first game ... I'm doing my warm up, I've set up. Everybody warms up doing the static stretching but I do the keep ball normally with just the players that are starting. The other subs just play with a ball. He [Derek] questioned me a little bit the first time. He says, 'Well, I don't agree with that.' I'm thinking 'What do I do? Do I tell this guy straight away, "Listen, pal, this is how we do it", or do I let him have his moment in the sun until I work him out?' I said, 'Alright, I'll put them [players] in.' Because to me, it doesn't really matter. It's just a warm up.

Jack continued to explain his political behaviour in appraising Derek: 'I thought, "Well, hang on a minute. I know I'm safe for bit." I needed to keep hold of him, he was doing a specific job that I couldn't do so there was no point sacking him. I have to figure out these guys in time. I let him have his moment in the sun: "there you go". I've let him have his little piece, but I'm sussing him out already. I'm sussing people out all the time. You think, "Can I work with him? Are they good at their job? Is he giving me what I need?".' Such micro-political behaviour as exhibited by Jack can be evident during organisational change, as uncertainty and conflict generated during these periods "intensifies political activity around the processes and outcomes of the changes being introduced" (Buchanan, 1999, p. 573). Furthermore, Ferris et al. (2002) have suggested that the experienced political actor is one who can masquerade their self-serving intent. 
Following this period of appraisals, Jack was asked to discuss his thoughts with the 1st Team Manager, where he felt he was 'becoming responsible for people's jobs'. Jack provided an insight into these discussions with the 1st Team Manager:

Was he [Michael] very good at his job? From my experience of working in youth, yes. Did he have any complaints coming back about him? No. So, he worked quietly and efficiently. Was he the bee's knees and the best coach in the world? Probably not. But when the Gaffer [1st Team Manager] saw him coaching [and wasn't sure] ... I'm thinking 'Hang on a minute, he's very good at what he does, all of his staff turn up.' So, I might not agree with that and just say, 'No, he's alright.' So, I might be the one saving Michael. Then he might say 'What about Dave?' I'm thinking, 'Does he add value to me in my job?' Yes. So, I've got to fight for him. Before I know it, I'm becoming responsible for people's jobs. I had to make sure that when I asked for help in my job, at least $90 \%$ of the room would stand up and say, 'yeah, I'll help you'. So yeah, I had to keep everyone functioning so they would keep their staff within the academy functioning.

The decision by Jack to 'fight' for certain members of staff who 'add value' to his role is reflected in previous literature, where a degree of overlap between new and existing knowledge and practices is identified as a pre-requisite for the effectiveness of new knowledge and practices and the successful management of change (Ahuja and Katila, 2001). As described by Geppert and Dörrenbächer (2014), in the pursuit of self-interest actors will participate in internal politics related to issues such as resource allocation decisions and authority delegation and appointments. Jack also highlighted instances where he had to discuss staff with Dave, the 
Academy Manager: 'I said 'I can't work with him [Jerermy- Head of Youth Development Phase], he's doing my head in" ... Dave would say “Oh yeah, I know” ... "No, he’s f**king

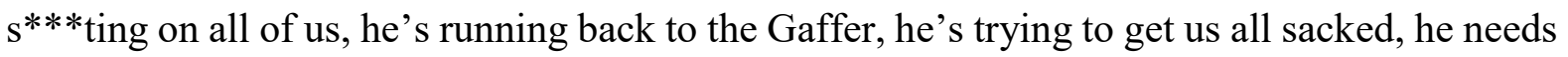
to go."' Jack's experiences of conversations with the 1st Team Manager about Jack's staff and Jack 'becoming responsible for people's jobs' highlight the strategy he used to influence the 1st Team Manager to ensure that the staff he needed to fulfil his remit remained at the club. Indeed, Nissen (2016) has highlighted the importance of a coach being consistent 'with the culture and strategy of the club ... to increase his trustworthiness and perhaps postpone a potential dismissal' (p. 146). Similar findings were reported by Author and Author (2018a) when dealing with members of staff who were not working in a manner that was associated with positive organisational change, and who subsequently 'moved on'.

Jack reflected on this process of coming into the club and the academy as an outsider and having so much responsibility in the change process and on the impact this had on him personally and his understanding of how others perceived him:

I think it would have been easier if I had come in in a group of three or four and we were all close-knit. Come in, carte blanche, you're doing this. It's about the surrounding people having to fit in with what you do, whereas I felt I had to fit into them first, get their trust and then change it. Rather than isolate myself in my working day which didn't feel comfortable in an office where they're all going ' $\mathrm{d} * * *$ head' behind my back.

Jack's awareness of the need to 'fit into them first' and 'gain their trust' before implementing a change to working practices highlights the importance that such an awareness has for the careful consideration of the construction of an identity upon employment within a 
new role. Such an approach reflects previous findings that the construction of an identity that is congruent with the desired identity of an existing social group is crucial in having influence over that group's members (DeRue and Ashford, 2010; Stavrakakis, 2008). Furthermore, the findings of Ogbonna and Harris (2015) suggest the importance of creating camaraderie within the working environment of a professional football club to achieve desired goals.

\section{First session with the players and challenges to identity}

Following his appraisals of the staff within the academy department, Jack had to meet the players within the U18 team: the squad that he would predominantly be working with. Jack discussed the first time he met the players and the effect this had on his sense of self and identity as a coach, and on his decisions on when and how to reveal his true self as a coach:

It's like being back at school for the first day, nerves are jangling. You're going to get judged, the lads are going to judge you straight away ... 'Don't like him' ... 'talks funny'. You know what it's like, a group of lads, they can rip you to bits. They're quite savage, even Under 18s. If you're weak with them, they can take you for a ride.

Jack continued to discuss the first training session with the players and his thoughts on the impression he wanted to portray to his new players during this initial training session:

So, I set up, I'm thinking, 'This doesn't look right, it's not how I want it, they're messing about, those two there ... do I rip them or do I just ...?'. I said, 'Oi, pay attention when I'm talking.' Go in easy, go in a bit nice. Then, eventually, I'm getting in to exactly who I am. 
The work of Sveningsson and Alvesson (2003), in their exploration of identity, provides a frame to understand how managers develop and work with their identity in strengthening, maintaining and revising the construction of 'the self' to portray a sense of distinctiveness and coherence. However, this study further contributes to our understanding of identity construction by illustrating that identity work is entwined with micro-political literacy and micro-political action (Kelchtermans, 2009; Kelchtermans and Ballet, 2002).

Furthermore, Jack was also wary of the perception of himself by the 1st Team Manager in the early periods of change. Whilst he had been assured of his relative 'safety', he didn't want the 1st Team Manager to question whether or not the right decision had been made to hire Jack. The Under 18s were due to play their first game with Jack in charge and the match had been postponed due to a waterlogged pitch:

We get there, it's lashing down. Pitch is under a bit of surface water. I want to play, I want to play, the referee is on the pitch. I watch to play; I want to play. I need to see these lads; I want to play. 'Gentleman. It's off.' $\mathrm{F}^{* *} \mathrm{k}$, so what do I do? 1st Team Manager says they're not fit enough. If I give them the weekend off, I'll look weak. Tell you what we'll do, get your kit on. We'll run on the front at Belton.

Within the context of professional football, the work of Wagstaff et al. (2016) demonstrated how periods of organisational change can elicit similar negative emotional responses to those described in the data above. The desire to be seen to be performing well during the change process is driven by employment vulnerability, which is an inherent structural condition of professional football (Author and Author, 2018a; Wagstaff et al., 2016). 


\section{Vulnerability and relationships with staff}

When discussing his feelings of vulnerability after being appointed, Jack reflected on the pressure he put on himself and the impact knowing that somebody had lost their job so he could be appointed had on him in the early stages of employment. Specifically, he stated: 'After the first week of training I wanted us to go out and smash [gain a big win] somebody but it's not realistic. There wasn't any pressure from the club, but I think I created my own pressure because I needed to impress. I have been brought in and somebody lost their job.'

In addition, Jack was aware of the effect that these issues around vulnerability had on the other members of staff he had to work with on a daily basis:

I started with the Gaffer [1st Team Manager], Bertie [Assistant Manager] and Freddie [1st Team Coach] who are the new staff who appointed me. But directly during the day, I was with Derek [Sport Scientist], Adam [Physiotherapist], Dave [Academy Manager] and Michael [Head of Foundation Phase] who were all part of the previous regime. I was lucky really because I knew I had the backing of the Gaffer because he had brought me in. Then the Chairman thinks you're great because the Gaffer has sold him the story about you. I'm like the new guy in town and now they were thinking 'What's happening with my job? Will he like me? Will he not? He's probably safe because the Gaffer has brought him in so he'll be alright for 12 months. What's gonna happen with me? Do I need to impress him?' There is a lot of things in football that are political. You find out after a month or so that you've probably sussed out what most people are like.

Jack's awareness of the potential fears and concerns that existing staff had in relation to an outside member of staff coming into the academy to lead them highlights the political 
dichotomy of managing a new group of staff. Indeed, leaders must be perceived by others as representative of the social group they are attempting to lead (Petriglieri and Stein, 2012). Croft et al. (2015) elaborate further to state that "leaders must be able to construct and communicate to other group members a desirable leader identity and a desirable social group identity" (p. 114). As part of creating such an identity, Alvesson and Sveningsson (2003) identify the importance of leaders in providing reassurance to related staff members. As highlighted above, such reassurance is significant during periods of change in the environment of professional football and it demonstrates the micro-political nature of leadership identity formation.

\section{Achieving goals}

Jack demonstrated the use of political action in knowing which members of staff within the club's hierarchy to approach with certain problems or to achieve certain goals:

It's understanding what the powers that be are like, what potentially could they do with this problem. So, it's knowing the staff - knowing that if something needs some weight behind it, going to the Chairman or a money man might be the answer ... Who might get in the way of that decision and prolong it? Miss them out. Does he need to know? He might do. If I'm writing an email I might CC him in so he knows, but he might not think it's to do with him, but he'll probably want to stick his nose in. It's just managing who can help you.

Jack's need to understand the appropriate political action within his day-to-dayworking practices highlights the importance of being "politically savvy" (Munyon, Summers, Thompson and Ferris, 2015, p. 145) when making decisions that may influence success within the working environment. Becoming politically savvy as a leader refers to the ability to 
understand the power and political dynamics of an organisation (Chao, O'Leary-Kelly, Wolf, Klein and Gardner, 1994).

\section{Managing academy impressions}

After settling in at the football club and achieving relative success in terms of the remit given to him, Jack was aware of the importance of managing the impressions of the academy within the football club. In particular, Jack wanted to ensure that each academy player who had made a first team debut was promoted around the training ground:

There's a lot you have to think about. Gaffer's got all these pictures now and made it a lot better. But I've been in to the Chairman today to say there's nothing on our debuts for the last three years, not one. Chairman said, 'Brilliant this'. So, we've got it. I wanted to sell ourselves better.

Jack's desire to have pictures of the academy players who had made first team debuts put up around the ground aimed to enhance the identity regulation of a successful academy. Regulating a positive identity within the working environment has been found to create a stronger culture and commitment amongst employees (Alvesson and Willmott, 2002). Zhang and Rajagopalan (2010) argued that a new leader "may also make changes to signify that his or her era differs from that of the predecessor" (p. 343).

In addition to ensuring that the academy was promoting its success, Jack also highlighted the importance of protecting good players from being judged incorrectly by the 1st Team Manager: 
One of the lads isn't training well, his attitude has been off. I don't need to share that with everybody, he's a good kid, he's got a chance. I might let Barbara [Welfare Officer] know ... 'just go and have a chat with him, see if everything's alright'. That's it. That's as far as it goes. If it goes to the Gaffer ... ' $\mathrm{F}^{* *} \mathrm{k}$ him off, bad attitude'. But he's not! It's not that severe, it's managing how we are perceived, managing how we are viewed in social media, and what goes out in the media about the academy.

\section{Sources of self-doubt}

During those early stages of change and coming into his new role, Jack experienced instances of self-doubt in certain circumstances. Jack recalled one instance where this happened, when dealing with the players in his first team talk before his first competitive game with the Under 18s:

I still remember it to this day. We were playing Beresford [pseudonym]. A lot of the second years [players in the final year of their full-time scholarship] were there and I had invited some of the Under 16s in as subs and to plan for next year. So, in my head I'm planning for next year, playing Beresford. So, I'm in the dressing room and I've got Dave [Academy Manager] with me. So, I'm doing the team talk before the game and there's some sniggering down the far end of the dressing room. What do you say ... 'What you laughing at? What's the joke?' In my head, I'm thinking, 'I've got the $16 \mathrm{~s}$ in the room, these second years are laughing. The 16s can see them laughing.' So I go down there ... 'What's going on?' I was thinking ' $\mathrm{F}^{* *}$ king hell, Dave's here' ... Is he thinking 'He can't control the group' ... He's gonna go back to Michael [Head of Foundation] and 
the lads and say, 'Should have seen it!' So, I've nailed [berated] them before the game.

Jack continued his explanation:

In my head ... Dave's thinking 'He doesn't know what he's doing', which he probably did. He never admitted it but he probably did. You're not looking forward to going in the next day ... Are the lads going to take the $\mathrm{p}^{* *}$ s again, or do I have to jump on them? Do I have to just forget it, but if I do that are they going to corrupt the Under 16s?

Such encounters have the power to spark a process of critical reflection on 'turning points' or 'key experiences' for managers and leaders during identity work (Kelchtermans, 2009; Sveningsson and Alvesson, 2003). Alvesson and Willmott (2005) suggest that such reflective instances of self-doubt and self-openness can lead to a negative construction of selfidentity brought about by "psychological-existential worry faced during encounters with others" (p. 626). Furthermore, the work of Croft et al. (2015), in the nursing profession, found that "managers reported the biggest source of their identity conflict was their perceived loss of group influence, and the feeling they were no longer able to construct a desired ... identity" (p. 124).

Therefore, this paper adds a rich in-depth insight that builds upon our current understanding of 'identity work', illustrating that the process of developing a leadership identity can be significantly influenced by micro-political literacy (seeing) and micro-political action (doing) in the way that leaders view themselves and importantly how they want to be viewed by others within organisations. Such action is structurally constrained by leaders' own perceptions of employment vulnerability (i.e. the consequences of actions upon employment 
tenure and effectiveness). In particular, this paper highlights the complex micro-political struggle and the emotional nature of identity work required to further our understanding of organisational life.

\section{Conclusion}

This purpose of this paper was to further our understanding of the construction of a professional leadership identity of an outsider appointed during a period of organisational change. Jack was appointed by the Chairman because Smithstown FC had not developed players for the $1^{\text {st }}$ Team for a period of seven years. However, upon undertaking the employment it became clear that developing players for the club to sell as part of a successful business model was the primary focus of his role. To help achieve this, Jack engaged in a process of appraising whether the current staff within his new department would be 'useful' in supporting him in addressing the business remit, or not. Simultaneously, he constructed a professional identity to influence others by winning their 'trust' and to avoid becoming 'isolated' within the organisation or viewed as 'weak', with the principal goal of protecting his employment status (Kelchtermans, 2006, 2009). The analysis illustrated how Jack perceived that the appraisal of others, both internally (e.g. Jack's role performance) and externally (e.g. the perceived standing and performance of the academy), affected his employment vulnerability (Kelchtermans, 2006, 2009). In an attempt to manage this vulnerability, Jack engaged in 'identity work', which was intertwined with micro-political literacy (seeing) and micro-political action (doing) to improve his working conditions for effective role performance (Kelchtermans, 2006, 2009; Kelchtermans and Ballet, 2002; Sveningsson and Alvesson, 2003). An unintended consequence of this micro-political action, for Jack, was becoming responsible for other peoples' jobs, that is, those that he fought to protect (Balogun and Johnson, 2005; Heyden et al., 2017). In addition, the analysis of Jack's narrative illustrates how the development of a managerial identity through identity work is a complex, political, emotional and contested 
endeavour, fraught with vulnerability, periods of self-doubt and critical instances that often require critical reflection during managerial identity formation (Kelchtermans, 2006, 2009; Sveningsson and Alvesson, 2003).

\section{Theoretical implications}

Whilst earlier work investigating organisational change in sport has highlighted the environmental forces driving change (Wealty Peachey and Bruening, 2011), the influences on changing organisational culture (Cruickshank, Collins and Minten, 2013) and the responses to change (Wealty Peachey and Bruening, 2012; Wagstaff et al., 2016), this study is the first to examine the micro-political nature of implementing organisational change as an outsider in professional youth football. Previous work has highlighted the impact of outside change agents on organisational performance (Zhang and Rajagopalan, 2010); however, the narrative data within this study provides an insight into the day-to-day working life of an outsider tasked with implementing organisational change. Specifically, this paper furthers our empirical understanding of the social complexities at play during the construction of a professional leadership identity of an outsider coming into a new organisation to implement organisational change (Alvesson and Sveningsson, 2003a; Alvesson and Sveningsson, 2003b; Alvesson and Willmott, 2002; Croft, et al., 2015; Sveningsson and Alvesson, 2003; Zhang and Rajagopalan, 2010).

In particular, this work is the first to provide a novel empirical and theoretical examination of the role of micro-political literacy, micro-political action, employment vulnerability and emotions in managerial identity work (Kelchtermans, 2006, 2009; Kelchtermans and Ballet, 2002; Sveningsson and Alvesson, 2003) as an agent of change. Whilst previous work has focused on the construction of leadership identities (Croft et al., 2015), this paper has highlighted the importance of constructing a professional leadership identity, as an outsider, in 
order to successfully implement organisational change. As an outsider, through the micropolitical activity involved when managing professional working relationships with the Chairman, Directors and $1^{\text {st }}$ Team Management, the participant successfully achieved the remit he was tasked with upon his appointment. The development of effective relationships with the staff that he was responsible for were also key in achieving this remit.

When contextualising the findings within the broader, existing management leadership literature, important differences become apparent in our study, which reflect the authoritarian culture and structural employment vulnerability in professional youth football. For example, the data presented demonstrate how Jack's actions and strategies in the development of his professional leadership identity were driven by an overriding concern with his personal identity (e.g. how he was viewed as a competent professional; 'I' and 'me') (Turner, 1982), rather than by a desire to build a sense of social identity (e.g. as a group working towards shared goals; 'us' and 'we') (Steffens et al., 2014; Turner, 1982). Similarly to the work of Kelchtermans (2006, 2009) in teaching, the development of a highly personalised professional identity in such cultures is often driven by structural employment vulnerability and a desire to maintain employment. Indeed, whilst recognising his own employment vulnerability when working in professional football, Jack openly discussed how staff members would lose their employment if he deemed that they did 'not add value to his role'. This contrasts with previous work by Petriglieri and Stein (2012, p.114) who highlight that 'leaders must be perceived by others as representative of the social group they are attempting to lead'. Even in situations where Jack referred to 'how we [the academy] are perceived', from a social group identity perspective, the underlying motivation was to protect his own personal and professional identity (e.g. if he is viewed as doing a good job through the academy performing well). This case study further demonstrates how social groups and personal and social identities exist and interact in a complex manner within organisational life. Specifically, the case study illustrates how, as an 
outsider appointed to the organisation, Jack was more closely aligned to the new senior management team in his values and goals (e.g. Chairman and $1^{\text {st }}$ Team staff) than the staff that he worked with on a day-to-day basis in the academy. Indeed, this is an important feature of why Jack was appointed to the role initially to support organisational change within the academy.

\section{Practical implications}

The analysis of Jack's narrative as an outsider appointed to implement organisational change within professional youth football identified the importance of understanding the employment context and remit at the club, whilst being aware of the insecure nature of employment within professional football. For a practical perspective, outsiders appointed to competitive, dynamic organisations should endeavour to seek reassurances regarding tenure, senior managerial support and how they will be appraised (i.e. what does success/failure look like), whilst also clearly identifying areas of priority that offer potential quick wins and significant change. Practically, quickly changing the day-to-day working practices of different departments within the organisation (e.g. recruitment and coaching) should be addressed by outsider change agents to align working process to organisational goals as a priority.

In order to achieve the change that was required, Jack undertook a process of appraising his existing staff and making decisions based on a simple set of criteria (e.g. 'Can I work with him? Are they good at their job? Is he giving me what I need?'). Devising such criteria is recommended for outsiders when appraising staff who will be responsible for implementing and delivering the organisational goals outlined by the outsider. The remit, organisational goals, and personal values of the outsider should be the key influencers in devising such criteria. 
In addition, leaders that are appointed as outsiders to enact organisational change may be faced with situations where they are required to make important and confrontational decisions. Jack explained the importance of such situations as he was acutely aware of how existing members of staff would appraise his leadership ability (e.g. as a strong or weak leader). Furthermore, the manner in which staff talk 'and express sentiments about leaders' (Alvesson and Sveningsson, 2003a, p. 365) requires consideration when implementing organisational change. From a practical perspective, it is important to not only have a clear vision for change but also have the ability to enact the desired changes under internal scrutiny from subordinate members of staff. Jack explained the importance in these situations of developing and maintaining his own consistent leadership identity to avoid being questioned or undermined. Practically then, senior leaders appointed to initiate and support change need to be aware of how their decisions to act (or not) will be interpreted by existing employees as strong or weak leadership. It was clear that the success of his leadership was based upon his ability to act in a (micro)political manner, recognising the, at times, conflicting personal goals and agendas of those working within the organisation, whilst attempting to achieve his own goals in a manner that reduced resistance to change. Therefore, to be effective, senior leaders need to quickly identify who needs to be involved within the decision-making process and who needs to be informed of decisions once they have been taken. In addition to how information was communicated internally within the organisation, Jack made sure that the success of the changes became more visible by displaying pictures of the academy's success for everyone to see, thus reinforcing the value of the changes and his role. Practically, to retain his employment and to further increase his influence within the organisation, making everyone aware of the success appeared to be as important as the success itself. 


\section{Future directions in the study of organisational change in professional youth football}

Whilst this study has extended our understanding of the experiences of an outsider appointed to implement and support organisational change in professional youth football, there are still areas that require further attention. Indeed, the narrative account of Jack's story has provided us with the depth and detail of his own experiences (Sparkes \& Smith, 2014). However, scholarly investigation aimed at comparing and contrasting the experiences of other key stakeholders within similar professional football academy settings would provide us with an understanding of how social groups are formed in such settings during periods of organisational change. Moreover, as the strengths and limitations of a single-study design have previously been expressed (Author \& Author, 2018a; Jones, Armour \& Potrac, 2003), studies with a wider sample that includes a range of participants within an organisational setting would further our understanding of the formation of social groups within professional groups and the tensions that may or not exist throughout this process during a period of organisational change (Petriglieri \& Stein, 2012).

\section{References}

Ahuja, G., and Katila, R. (2001). Technological acquisitions and the innovation performance of acquiring firms: A longitudinal study. Strategic Management Journal 22: 197-220.

Alvesson, M., and Sveningsson, S. (2003a). The great disappearing act: Difficulties in doing “leadership". Leadership Quarterly 14: 359-381.

Alvesson, M., and Sveningsson, S. (2003b). Managers doing leadership: The extraordinarization of the mundane. Human Relations 56: 1435-1459.

Alvesson, M., and Willmott, H. (2002). Identity regulation as organisational control. Journal of Management Studies 39: 619-644.

Armenakis, A. A., and Bedeian, A. G. (1999). Organisational change: A review of the theory and research in the 1990s. Journal of Management 25: 293-315. 
Gibson, L., and Groom, R. 2018a. "Ambiguity, manageability, and the orchestration of organisational change: a case study of an English Premier League Academy Manager." Sport Coaching Review 7:1: 23-44.

Gibson, L., and Groom, R. 2018b. "The micro-politics of organisational change in professional youth football: towards an understanding of the 'professional self." Managing Sport \& Leisure 23:1-2: 106-122.

Gibson, L., and Groom, R. 2019. "The micro-politics of organisational change in professional youth football: towards an understanding of 'actions, strategies and professional interests'." International Journal of Sports Science \& Coaching 14:1: 3-14.

Balogun, J., and Johnson, G. (2005). From intended strategies to unintended outcomes: The impact of change recipient sensemaking. Organisation Studies 25: 1573-1601.

Berger, P., and Luckmann, T. (1996). The social construction of reality: A treatise in the sociology of knowledge. London, UK: Penguin Books.

Brown, A. D., and Coupland, C. (2015). Identity threats, identity work and elite professionals. Organisation Studies 36: 1315-1336.

Buchanan, D. A. (1999). The logic of political action: An experiment with the epistemology of the particular. British Journal of Management 10: 573-588.

Chao, G. T., O’Leary-Kelly, A. M., Wolf, S., Klein, H. J., and Gardner, P. D. (1994). Organisational socialization: Its content and consequences. Journal of Applied Psychology 79: 730-743.

Croft, C., Currie, G., and Lockett, A. (2015). The impact of emotionally important social identities on the construction of a managerial leader identity: A challenge for nurses in the English National Health Service. Organisation Studies 36: 113-131.

Cruickshank, A., Collins, D., and Minten, S. (2013). Culture change in a professional sports team: Shaping environmental contexts and regulating power. International Journal of Sports Science and Coaching 8: 271-290.

Denis, J. L., Langley, A., and Cazale, L. (1996). Leadership and strategic change under ambiguity. Organisation Studies 17: 673-699. 
DeRue, D., and Ashford, S. (2010). Who will lead and who will follow? A social process of leadership identity construction in organisations. Academy of Management Review 35: $627-647$.

Dörrenbächer, C., and Geppert, M. (2006). Micro-politics and conflicts in multinational corporations: Current debates, re-framing, and contributions of this special issue. Journal of International Management 12: 251-265.

Ferris, G. R., Hochwarter, C., Douglas, C., Blass, R., Kolodinsky, W., and Treadway, D. C. (2002). Social influence processes in organisations and human resource systems. Research in Personnel and Human Resources Management 21: 65-127.

Geppert, M., and Dörrenbächer, C. (2014). Politics and power within multinational corporations: mainstream studies, emerging critical approaches and suggestions for future research. International Journal of Management Reviews 16: 226-244.

Gilmore, S., and Gilson, C. (2007). Finding form: Elite sports and the business of change. Journal of Organisational Change Management 20: 409-428.

Heyden, M. L. M., Fourné, S. P. L., Koene, B. A. S., Werkman, R., and Ansari, S. (2017). Rethinking 'top-down' and 'bottom-up' roles of top and middle managers in organisational change. Journal of Management Studies 54: 961-1120.

Jones, R. L., Armour, K., and Potrac, P. (2003). Constructing expert knowledge: a case study of a top-level professional soccer coach. Sport, Education \& Society 8: 213-229.

Kelchtermans, G. (2006). Teacher vulnerability: Understanding its moral and political roots. Cambridge Journal of Education 26: 307-323.

Kelchtermans, G. (2009). Who I am in how I teach is the message: Self-understanding, vulnerability and reflection. Teachers and Teaching 15: 257-272.

Kelchtermans, G., and Ballet, K. (2002). The micropolitics of teacher induction. A narrativebiographical study on teacher socialisation. Teaching and Teacher Education 18: 105120.

Koveshnikov, A., Vaara, E., and Ehrnrooth, M. (2016). Stereotype-based managerial identity work in multinational corporations. Organisation Studies 37: 1353-1379.

Munyon, T. P., Summers, J. K., Thompson, K. M., and Ferris, G. R. (2015). Political skill and work outcomes: A theoretical extension, meta-analytic investigation, and agenda for the future. Personnel Psychology 68: 143-184.

Nissen, R. (2016). Hired to be fired? Being a coach in Danish professional football. International Journal of Sports Science and Coaching 11: 137-148. 
Ogbonna, E., and Harris, L. C. (2015). Subcultural tensions in managing organisational culture: A study of an English Premier League football organisation. Human Resource Management Journal 25: 217-232.

Petriglieri, G., and Stein, M. (2012). The unwanted self: Projective identification in leaders' identity work. Organisation Studies 33: 1217-1235.

Petrou, P., Demerouti, E., and Schaufeli, W. B. (2018). Crafting the change: The role of employee job crafting behaviors for successful organisational change. Journal of Management 44: 1766-1792.

Pettigrew, A. M., Woodman, R. W., and Cameron, K. S. (2001). Studying organisational change and development: Challenges for future research. Academic Management Journal 44: 697-713.

Polkinghorne, D. E. (2007). Validity issues in narrative research. Qualitative Inquiry 13: 471486.

Roderick, M. (2006). A very precarious profession: uncertainty in the working lives of professional footballers. Work, Employment and Society 20: 245-265.

Ruddin, L.P. (2006). You can generalize stupid! Social scientists, Bent Flyvbjerg, and case study methodology. Qualitative Inquiry 12: 797-812.

Smith, B. (2013). Sporting spinal cord injuries, social relations, and rehabilitation narratives: An ethnographic creative non-fiction. Sociology of Sport Journal 30: 132-152.

Smith, B., and Sparkes, A. C. (2005). Men, sport spinal cord injury, and narratives of hope. Social Science and Medicine 61: 1095-1105.

Sparkes, A. C., and Smith, B. (2008). Narrative constructionist inquiry. In Handbook of constructionist research, edited by J. Holstein, and J. Gubrium, 295-314. London, UK: Guilford Publications.

Sparkes, A. C., and Smith, B. (2014). Qualitative research in sport, exercise and health: from process to product. London, UK: Routledge.

Stavrakakis, Y. (2008). Peripheral vision. Organisation Studies 29: 1037-1059.

Steffens, N. K., Haslam, S. A., Reicher, S. D., Platow, M. J., Fransen, K., Yang, J., Jetten, J., Ryan, M. K., Peters, K. O., and Boen, F. (2014). Leadership as a social identity management: introducing the Identity Leadership Inventory (ILI) to assess and validate a four-dimensional model. Leadership Quarterly 25: 1004-1025.

Sveningsson, S., and Alvesson, M. (2003). Managing managerial identities: Organisational fragmentation, discourse and identity struggle. Human Relations 56: 1163-1193. 
Thacher, D. (2006). The normative case study. American Journal of Sociology 111: 1631-76.

Thomas, G. (2016). How to do your case study (2nd ed.) London, UK: Sage.

Turner, J. C. (1982). Towards a redefinition of the social group. In Social identity and intergroup relations, edited by $\mathrm{H}$. Taijfel, 15-40. Cambridge, UK: Cambridge University Press.

Van de Ven, A. H., and Poole, M. S. (2005). Alternative approaches for studying organisational change. Organisation Studies 26: 1377-1404.

Wagstaff, C., Gilmore, S., and Thelwell, R. (2016). When the show must go on: Investigating repeated organisational change in elite sport. Journal of Change Management 16: 3854.

Wealty Peachey, J., and Bruening, J. (2011). An examination of environmental forces driving change and stakeholder responses in a football championship subdivision athletic department. Sport Management Review 14: 202-219.

Wealty Peachey, J., and Bruening, J. (2012). Investigating ambivalence towards organisational change in a football championship subdivision intercollegiate athletic department. Sport Management Review 15: 171-186.

Wright, C., Nyberg, D., and Grant, D. (2012). "Hippies on the third floor": Climate change, narrative identity and the micro-politics of corporate environmentalism. Organisation Studies 33: 1451-1475.

Zhang, Y., and Rajagopalan, N. (2010). Once an outsider, always an outsider? CEO origin, strategic change, and firm performance. Strategic Management Journal 31: 334-346. 